\title{
Fertilization Failure in Gadids: Aspects of its Measurement
}

\author{
Douglas F. Markle 1 \\ Huntsman Marine Laboratory \\ St. Andrews, New Brunswick, Canada EOG 2X0 \\ and \\ Kenneth G. Waiwood \\ Marine Fish Division, Department of Fisheries and Oceans \\ Biological Station, St. Andrews, New Brunswick, Canada EOG 2X0
}

\begin{abstract}
Recent studies implicate the old idea of fertilization failure as a potential cause of early "mortality"in some fishes. Laboratory studies with cod (Gadus morhua) and pollock (Pollachius virens) indicate that detection of unfertilized eggs in plankton samples may be difficult but that this can be enhanced by an acidic fixative and gentle capture methods. Morphogenesis of unfertilized eggs does not seem to be strongly canalized: eggs may or may not become activated, form a "blastodisc" or form cytoplasmic "atolls" or "islets". However, the latter seems to be a distinctive feature of unfertilized eggs. Analysis of 9,894 field-caught eggs that were fixed in Stockard's solution showed that $40 \%$ were mechanically damaged (perivitelline membrane destroyed) and at least $3.7 \%$ of the remaining precleavage eggs were unfertilized.
\end{abstract}

\section{Introduction}

Studies of fish population dynamics have revealed great variability in survival from egg to mature fish among different species and different year-classes of the same species (Braum, 1978). Much of this variability appears attributable to mortality in egg and larval stages, but the causes of the mortality are difficult to analyze. Fertilization failure was thought by some researchers to be the principal cause of mortality in cod eggs (Earll, 1880; Apstein cited by Dannevig, 1919; Howell, 1921; McKenzie, 1940). Other workers thought that certain opaque eggs in plankton samples were unfertilized or mechanically damaged (Mclntosh and Prince, 1890; Rollefsen, 1930). Rollefsen (1932) demonstrated that one cause was mechanical damage, but some recent workers (Williams et al., 1973; Hempel, $1965,1979)$ have accepted this as the sole cause and dismissed the question of fertilization failure.

The elaborate spawning rituals and specializations (e.g. intromittent organs, parasitic males and synchronous hermaphrodity) that some fishes have to ensure fertilization are a strong "indication of the relative inherent weakness of this point in the life chain" (Breder and Rosen, 1966). Recent aquarium studies on pomacanthids (Bauer and Bauer, 1981), characids (Nakatsura and Kramer, 1982), and squid (O'Dor et al., 1982) show that fertilization success of pelagic spawners, even those with elaborate courtship behavior, can be extremely variable $(0-100 \%)$. In another recent study, Middaugh and Takita (1983) showed that Menidia menidia spawn at low current velocities (slack water), presumably to reduce milt dispersion and increase the likelihood of fertilization. The relatively high $(92-99 \%)$ fertilization success in salmonids with substrate spawning (Braum, 1978) may therefore be an inappropriate level to use for other fishes (Hempel, 1965).

If fertilization failure is accepted as an important "mortality" factor in some species, there are formidable obstacles to the demonstration of this variability in the field. In this paper, the effects of fixative and damage on morphology of fertilized eggs of pollock ( $\mathrm{PO}$ lachius virens) and Atlantic cod (Gadus morhua) are examined, and the results are applied to 29 field samples from the southern Gulf of St. Lawrence.

\section{Materials and Methods}

Pollock and cod were caught as juveniles and reared for 2-3 yr in circular tanks (420-3,390 I capacity). Sea water from Passamaquoddy Bay (salinity 28.00-30.00) was used in a continuous-flow system. Water temperature was at ambient levels except in summer when it was not permitted to exceed $9^{\circ} \mathrm{C}$ and during the experimental period (December-April) when it was maintained at $6.0^{\circ} \pm 0.5^{\circ} \mathrm{C}$. Flow rates provided $95 \%$ replacement of the water in the tanks in 4-5 hr.

Present address: Department of Fisheries and Wildlife, Oregon State University, Corvallis, Oregon, USA 97331 
Initial attempts to strip eggs from fish were unsuccessful and, with a limited number of adults, it was considered not feasible to risk repeated attempts. Eggs were therefore obtained from non-induced spawning in tanks which contained only females (unfertilized) or both males and females (fertilized). Ripe males were tagged during these experiments to facilitate subsequent identification. All tanks were checked for eggs at least twice daily during the experimental period. The exact time of egg release was unknown, but it could be estimated, at least for fertilized eggs, from the known developmental rate at $6^{\circ} \mathrm{C}$ (Earll, 1880; Howell, 1921; Meek, 1924; Bonnet, 1939; Fredgeirsson, 1978: Hardy, 1978). From casual observations, it was evident that most of the spawning occurred during the early morning.

When eggs were first noticed in the holding tanks, they were gently removed with a fine-mesh dipnet (fitted with 50-ml glass beaker codend) and placed in incubation chambers for subsequent sampling. Incubation chambers consisted of styrene acrylonitrile Imhoff cones (1-Icapacity) which were equipped with small aerators and suspended in a $6^{\circ} \mathrm{C}$ water bath. The incubation experiments involved fertilized pollock eggs from spawning on 19 January 1982, unfertilized pollock eggs from spawning on 14 February 1982, and unfertilized cod eggs from spawning on 24 March 1982.

For pollock, two subsamples of eggs were taken usually at the beginning of, and at intervals during, the incubation experiment. One of these was mechanically damaged by vigorous shaking (Rollefsen, 1932) prior to fixation and the other was left undamaged. The eggs were fixed in Stockard's solution (5\% formalin, $4 \%$ glacial acetic acid, $6 \%$ glycerine and $85 \%$ distilled water), a standard fixative for embryological work (Costello et al., 1957; Galat, 1972). Sample sizes ranged from 24 to 184 eggs for the two pollock experiments.

For cod, four samples of eggs were taken at each sampling time, two of which (randomly chosen) were mechanically damaged by shaking prior to fixation. Eggs from a damaged and an undamaged sample were fixed in Stockard's solution and the remaining two samples were fixed in phosphate-buffered $5 \%$ formalin at $\mathrm{pH}$ 6.7. Sample sizes during this experiment ranged from 20 to 116 eggs.

Field samples of eggs were collected during an ichthyoplankton survey of the southern Gulf of St. Lawrence by the research vessel $E$. E. Prince during 11-19 June 1982. Tows were made obliquely from 15, 35 or $50 \mathrm{~m}$ to the surface with $60-\mathrm{cm}$ bongo nets (Posgay and Marak, 1980) and at the surface with bongo and $1-m$ ring nets. Non-quantitative samples of eggs were gently removed from 29 ichthyoplankton catches at sea and fixed in Stockard's solution.

\section{Results}

Incubated eggs were categorized according to the morphological sequence which was observed in fertilized pollock eggs from Stockard's solution, with one modification (category II) to accommodate bufferedformalin eggs and another (category V) to accommodate unfertilized eggs. The morphogenetic categories were as follows:

I. Egg lacks perivite!line space (Fig. 1C) which all other stages possess.

II. Egg uniform with no obvious cytoplasmic structure or organization (Fig. 1E).

III. Cytoplasm polarized but not strongly (Fig. 2A).

IV. Cytoplasm strongly polarized, forming a blastodisc (Fig. 2B).

V. Cytoplasm polarized, forming an "atoll" or variously arranged cytoplasmic "islets" (Fig. 1B).

VI. First cleavage, two cells (Fig. 2C).

VII. Second or subsequent cleavage, four or more cells (Fig. 2G).

The term "blastodisc", in this paper, includes the germinal area of the ovum from the time of cytoplasm polarization.

The pollock eggs from Stockard's solution were clearly superior to those from buffered formalin for determining the morphogenetic state of cytoplasm (e.g. compare Fig. $1 \mathrm{~A}$ to $1 \mathrm{E}$ and Fig. $2 \mathrm{E}$ to $2 \mathrm{G}$ ). Categorization of the fertilized poliock eggs (Table 1 ) indicated that $66 \%$ of the undamaged eggs and $51 \%$ of the damaged eggs had reached category $\mathrm{VI}$ after $3 \mathrm{hr}$ of incubation. Most of these eggs had probably been spawned about 2-3 hr before incubation, the total time being consistent with the observation by Fredgeirsson (1978) that first cleavage occurs in about $5 \mathrm{hr}$ at ambient temperature. Clearly, the small numbers of eggs in categories $\mathrm{VI}$ and $\mathrm{VII}$ at hour $0(1-3 \%)$ were from an earlier spawning. The few undamaged eggs in category IV (8\%) and damaged eggs in category $111(8 \%)$ at hour 12 may not have been fertilized. In the fertilized eggs from Stockard's solution, damaged eggs showed the same relative development sequence as undamaged eggs (III $\rightarrow$ IV $\rightarrow \mathrm{VI} \rightarrow$ VII).

The undamaged, unfertilized pollock eggs differed noticeably from the fertilized eggs in morphogenesis (Table 1), the difference being evident in comparison of Fig. 1A-1C with Fig. $2 A-2 C$ and $2 E$. None of the fertilized eggs were in category I (without perivitelline space) after incubation for 3 and $12 \mathrm{hr}$, whereas $19 \%$ of the undamaged, unfertilized eggs had not developed a perivitelline space after $7 \mathrm{hr}$. Blastodisc development (category IV) was also delayed, with only $14 \%$ showing the structure after $7 \mathrm{hr}$. Formation of the blastodisc did not occur in more than $50 \%$ of the eggs, but the cyto- 

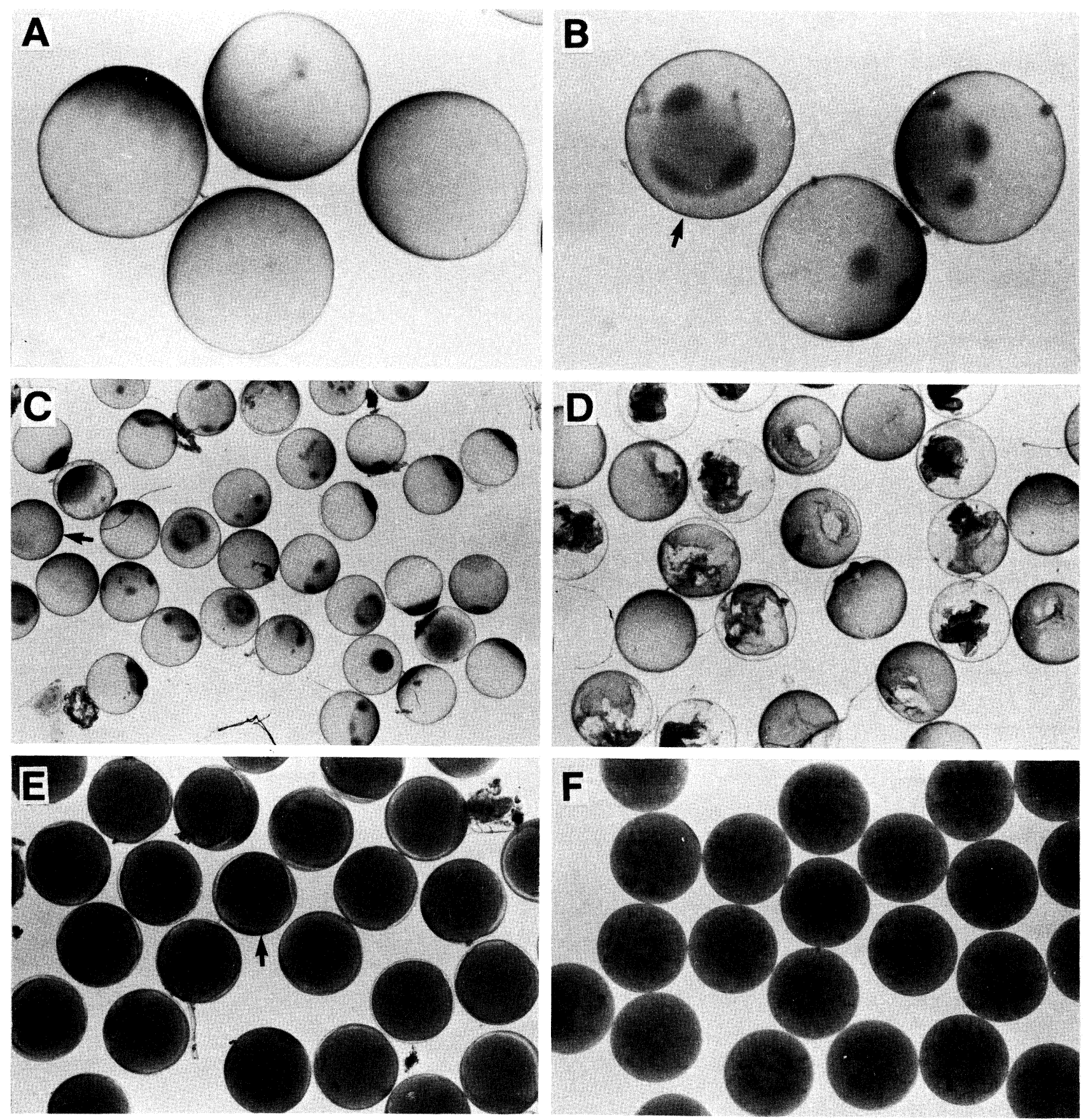

Fig. 1. Unfertilized eggs spawned on 14 February 1982 (pollock) and 24 March 1982 (cod). A, pollock, 2 hr after incubation showing egg category III. B, pollock, $7 \mathrm{hr}$ after incubation with all eggs in category V. C, pollock, $7 \mathrm{hr}$ after incubation showing variation in development, arrow indicates category I. D, cod, $1 \mathrm{hr}$ after incubation showing effect of damage. E, pollock, $2 \mathrm{hr}$ after incubation showing yolk opacity due to buffered formalin, arrow indicates category II. F, cod, $5 \mathrm{hr}$ after incubation showing effect of damage and buffered formalin. (A-D in Stockard's solution and $\mathbf{E}-\mathbf{F}$ in phosphate buffered formalin.)

plasm accumulated in an "atoll" after about $4 \mathrm{hr}$. Cortical alveoli were frequently present (not visible in Fig. 1), but cleavage did not occur in the unfertilized eggs. None of the damaged, unfertilized eggs had a perivitelline space (Table 1), and cortical alveoli were not present.
Comparison of the observations for the two series of undamaged cod eggs (Table 2) illustrates the difficulty of equating categories between the two fixatives. Up to $56 \%$ of the undamaged, formalin-fixed eggs had no identifiable perivitelline space (category I), whereas none of the eggs from Stockard's solution were in this 

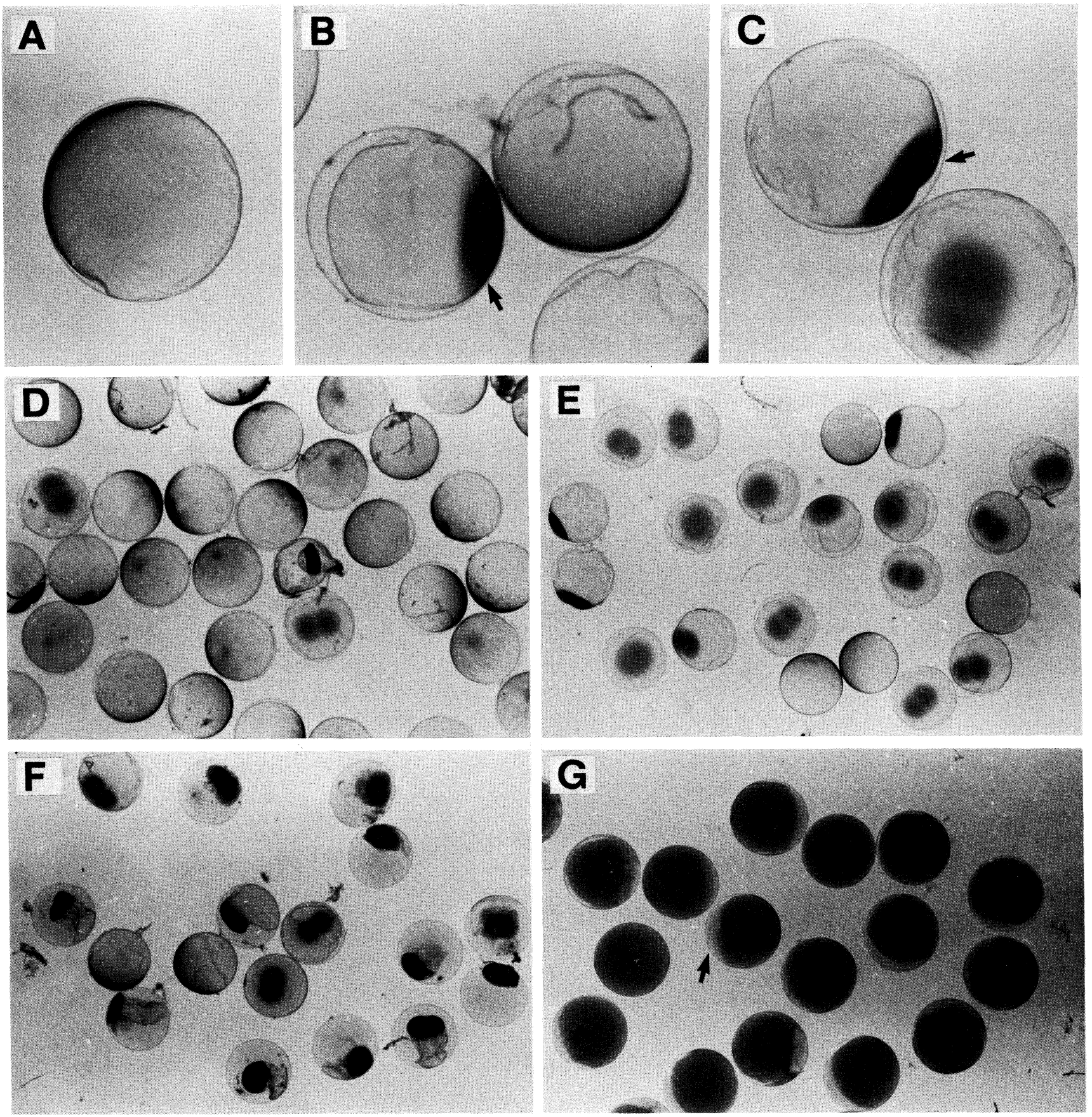

Fig. 2. Fertilized pollock eggs spawned on 19 January 1982. A, $3 \mathrm{hr}$ after incubation with cytoplasm polarized but not strongly (category III). B, $3 \mathrm{hr}$ after incubation showing egg (arrow) with strongly polarized cytoplasm (category IV). C, $3 \mathrm{hr}$ after incubation with two cells (category V). D, at the start of incubation showing variation in development. E, $3 \mathrm{hr}$ after incubation showing variation in development. F, $3 \mathrm{hr}$ after incubation showing effect of damage. G, $12 \mathrm{hr}$ after incubation showing effect of buffered formalin and 16-cell egg (arrow) in category VII. (A-F in Stockard's solution and $\mathbf{G}$ in phosphate buffered formalin.)

category. Due to the difficulty of seeing cytoplasmic structure in formalin-fixed eggs, none were assigned to category III (cytoplasmic polarization) and very few to category IV (blastodisc formation). In contrast, $85 \%$ or more of the eggs from Stockard's solution were assigned to category III and $10-15 \%$ to category IV. Damaged eggs from both fixatives were assigned mainly to category I. The capricious nature of mechan- ical damage is also apparent in the irregular occurrence of categories III and IV in the eggs from Stockard's solution. Category $\mathrm{V}$ was not observed in the unfertilized cod eggs (Table 2), but this category was evident in one-third of the unfertilized pollock eggs (Table 1) and has been observed recently in unfertilized eggs stripped from cod and white hake (Urophycis chuss). 
TABLE 1. Distribution of fertilized and unfertilized pollock eggs in various categories after incubation for certain periods and fixation in Stockard's solution. (See text for definition of egg categories I to VII.)

\begin{tabular}{|c|c|c|c|c|c|c|c|c|c|}
\hline \multirow[b]{2}{*}{ Treatment } & \multirow{2}{*}{$\begin{array}{c}\text { Hours of } \\
\text { incubation }\end{array}$} & \multirow{2}{*}{$\begin{array}{l}\text { No. of } \\
\text { eggs }\end{array}$} & \multicolumn{7}{|c|}{ Percent by egg category } \\
\hline & & & $T$ & 11 & III & IV & V & VI & VII \\
\hline \multicolumn{10}{|c|}{ Fertilized eggs, 19 January 1982} \\
\hline \multirow[t]{4}{*}{ Undamaged } & 0 & 181 & 8 & - & 87 & - & 1 & 3 & 1 \\
\hline & 1 & 184 & 12 & - & 20 & 67 & - & $\ldots$ & 1 \\
\hline & 3 & 44 & - & - & 9 & 20 & 4 & 66 & - \\
\hline & 12 & 28 & - & - & - & 8 & - & - & 92 \\
\hline \multirow[t]{4}{*}{ Damaged } & 0 & 92 & - & - & 98 & - & - & - & 2 \\
\hline & 1 & 87 & - & - & 5 & 95 & - & - & - \\
\hline & 3 & 49 & - & - & 6 & 43 & - & 51 & - \\
\hline & 12 & 24 & - & - & 8 & - & - & - & 92 \\
\hline
\end{tabular}

\section{Unfertilized eggs, 14 February 1982}

\begin{tabular}{llrrrrrrrr} 
Undamaged & 2 & 53 & 8 & - & 92 & - & - & - & - \\
& 4 & 96 & 9 & - & 58 & 1 & 32 & - & - \\
& 7 & 120 & 19 & - & 31 & 14 & 35 & - & - \\
Damaged & 4 & 158 & 100 & - & - & - & - & - & - \\
\hline
\end{tabular}

TABLE 2 Distribution of unfertilized cod eggs in various categories after incubation for different periods and fixation in two different solutions. (Eggs were spawned on $24 \mathrm{March}$ 1982; see text for definition of egg categories.)

\begin{tabular}{|c|c|c|c|c|c|c|c|}
\hline \multirow[b]{2}{*}{ Treatment } & \multirow{2}{*}{$\begin{array}{l}\text { Hours of } \\
\text { incubation }\end{array}$} & \multirow{2}{*}{$\begin{array}{c}\text { No. of } \\
\text { eggs }\end{array}$} & \multicolumn{5}{|c|}{ Percent by egg category } \\
\hline & & & 1 & 11 & III & IV & $\mathrm{V}-\mathrm{VII}$ \\
\hline \multicolumn{8}{|c|}{ Eggs fixed in Stockard's solution } \\
\hline \multirow[t]{4}{*}{ Undamaged } & 1 & 39 & - & - & 100 & - & -- \\
\hline & 3 & 39 & - & - & 90 & 10 & - \\
\hline & 5 & 31 & - & - & 87 & 13 & - \\
\hline & 7 & 34 & - & - & 85 & 15 & - \\
\hline \multirow[t]{5}{*}{ Damaged } & 0 & 45 & 100 & - & - & - & - \\
\hline & 1 & 63 & 35 & - & 65 & - & - \\
\hline & 3 & 40 & 97 & - & 3 & - & - \\
\hline & 5 & 32 & 100 & - & - & - & - \\
\hline & 7 & 37 & 87 & - & - & 13 & - \\
\hline \multicolumn{8}{|c|}{ Eggs fixed in buffered formalin } \\
\hline \multirow[t]{5}{*}{ Undamaged } & 0 & 116 & 91 & 9 & - & - & - \\
\hline & 1 & 48 & - & 100 & - & - & - \\
\hline & 3 & 36 & 39 & 61 & - & - & - \\
\hline & 5 & 34 & 56 & 40 & - & 4 & - \\
\hline & 7 & 23 & 26 & 65 & - & 9 & - \\
\hline \multirow[t]{5}{*}{ Damaged } & 0 & 75 & 100 & - & - & - & - \\
\hline & 1 & 69 & 100 & - & - & - & - \\
\hline & 3 & 38 & 100 & - & - & - & - \\
\hline & 5 & 48 & 100 & - & - & - & - \\
\hline & 7 & 20 & 100 & - & - & - & - \\
\hline
\end{tabular}

The 29 field samples from the Gulf of St. Lawrence contained 9,894 eggs, with Atlantic mackerel (Scomber scombrus) being the dominant species ( $95.7 \%$ of the total). Other species included Atlantic cod, yellowtail flounder (Limanda ferruginea), American plaice (Hippoglossoides platessoides) and fourbeard rockling (Enchelyopus cimbrius). Mechanical damage, presumably by natural causes (e.g. waves), capture and ship-board handling appeared to have been great $(3,962$ eggs or $40 \%$ were category I). Only 161 eggs could be placed in categories II, III, IV and V. Of these, three were definitely category $V$. These three eggs and three category IV eggs from the same sample had cortical vesicles which suported the interpretation that they were unfertilized. All six eggs were S. scombrus and were from a surface tow with a 1-m ring net.

\section{Discussion}

The foregoing observations indicate that the extent of fertilization success in nature cannot be established from ichthyoplankton samples that are preserved in near-neutral buffered formalin. Cytoplasmic changes, whether caused by fertilization or damage, were more easily detected when eggs were fixed in Stockard's solution (Tables 1 and 2), and, unless specified otherwise, the following discussion refers to eggs fixed in Stockard's solution.

Morphogenesis of fertilized and unfertilized eggs (undamaged) included formation of a perivitelline space, polarization of cytoplasm and blastodisc formation (Table 1). Similar examples have been reported by Ryder (1884) and Laale (1980). Most fertilized eggs had formed a blastodisc 1-3 hr after incubation (presumed 3-6 hr old), whereas only $14 \%$ of unfertilized eggs had formed a blastodisc after $7 \mathrm{hr}$ of incubation. Thus, it would not be possible to ascribe age or fertilization to a wild-caught egg with a blastodisc.

Some $(32-35 \%)$ unfertilized pollock eggs formed atoll-like cytoplasmic structures: (category $V$ in Table 1; Fig. $1 \mathrm{~B}$ and $1 \mathrm{C}$ ). More recent observations on stripped cod and white hake eggs indicate that these structures are frequently present in unfertilized eggs. 
From the field samples, these structures are also formed in unfertilized mackerel eggs. A few presumably-fertilized pollock eggs $(<1 \%)$ also formed these structures (Table 1), indicating that the eggs were not fertilized. Category IV seems to be the only category that might be an indicator of fertilization failure. However, because this category occurred rarely in the fertilized samples, it may also indicate a postfertilization breakdown in development. Regardless of the actual mechanism, it appears that normal development does not proceed through category $\mathrm{V}$, and, therefore, this category is associated with fertilization or immediate post-fertilization failure. Unfortunately, few of the unfertilized eggs reached this category (Tables 1 and 2).

Mechanical damage complicated the interpretation of egg categories. In formalin, there was relatively little observable difference between undamaged and damaged cod eggs (Table 2). In Stockard's solution, damaged eggs were more frequently distinguished from undamaged eggs.

Breakdown of cortical alveoli (cortical reaction) is associated with fertilization and may or may not be associated with formation of the perivitelline space (Ryder, 1884; Yamamoto, 1961; Nakano, 1969; Laale, 1980). Davenport et al., (1981) showed that, after $6 \mathrm{hr}$, unfertilized cod eggs formed a perivitelline space, retained cortical alveoli and showed no accumulation of cytoplasm. The present results concur with those observations in the formation of a perivitelline space and the presence of cortical alveoli in some unfertilized, undamaged eggs from Stockard's solution, but cytoplasmic accumulation was common in unfertilized eggs (categories IV and V).

Unfertilized eggs do not seem to have a canalized morphogenesis. If "activated", they appear to form blastodiscs and "atolls" (categories IV and V). If not activated, unfertilized eggs show only slight cytoplasmis polarization (category III) and retain most cortical alveoli. Detection of unfertilized field-caught eggs, therefore, seems to depend on use of Stockard's solution or a comparable acidic fixative, gentle capture methods to avoid complications associated with damage, and discovery of category $\mathrm{V}$ eggs or eggs with alveoli in categories III or IV.

The field samples were collected during a regular ichthyoplankton survey, and they probably reflect the quality and variability in sample condition that might be expected from a large-scale program which operates under conditions or variable weather and personnel. The perivitelline membrane was ruptured in $40 \%$ of the eggs. All of these were early-stage eggs (preblastopore closure), and, although cells could be seen in many cases, the presence or absence of cleavage could not consistently be determined in all category I eggs. Thus, the latter could not be used to determine the relative proportions of fertilized and unfertilized eggs. However, it was observed that 161 eggs could be placed in the precleavage categories II to $\mathrm{V}$, and six of these $(3.7 \%)$ were apparently unfertilized. More gentle methods of capture are clearly needed to improve upon these observations.

If mortality in planktonic fish eggs is worth investigating, some consideration of spatial and temporal variation in fertilization success is merited. Unfertilized eggs will sink, but they will also have a certain "life time" in the water column. Hydrographic conditions, such as upwelling and thermal stratification, might increase their suspension time or even aggregate them separately from the more buoyant eggs in wind generated Langmuir spirals (Stommel, 1949; Stavn, 1971). If the transparency of a normally developing egg is protection against visually oreinted planktivores (Breder, 1962), the opacity of unfertilized or dead eggs could increase their susceptibility to visual feeders such as fish larvae (Hunter, 1981).

\section{Acknowledgements}

We are grateful to M.-I. Buzeta, and L. A. Frost for technical assistance, W. McMullon and D. Aiken for photographic help, and E. Kjørsvik and J. F. McElman for reviewing a draft of the manuscript.

\section{References}

BAUER, J. A., Jr., and S. E. BAUER. 1981. Reproductive biology of pigmy anglefishes of the genus Centropyge (Pomacanthidae). Bull. Mar. Sci., 31: 495-513.

BONNET, D. D. 1939. Mortality of the cod egg in relation to temperature. Biol. Bull. Mar. Biol. Lab. Woods Hole. Mass.. 76: 428-441.

BRAUM, E. 1978. Ecological aspects of the survival of fish eggs, embryos, and larvae. In Ecology of freshwater fish production (p. 102-131), S. D. Gerking (ed.), J. Wiley and Sons, New York. N.Y., 520 p.

BREDER, C. M., Jr. 1962. On the significance of transparency in osteichthid fish eggs and larvae. Copeia, 1962: 561-567.

BREDER, C. M., and D. E. ROSEN. 1966. Modes of reproduction in fishes. Natural History Press, Garden City, New York, N.Y., 941 p.

COSTELLO, D. P., M. E. DAVIDSON, A. EGGERS, M. H. FOX, and C. HENLEY. 1957. Methods for obtaining and handling marine eggs and embryos. Marine Biol. Lab., Woods Hole, Mass., 247 p.

DANNEVIG, A. 1919. Canadian fish eggs and larvae. In Canadian fisheries expedition, 1914-1915 (p. 1-74), Dept. Naval Serv., King's Printer, Ottawa, $495 \mathrm{p}$.

DAVENPORT, J., S. LONNING, and E. KJФRSVIK. 1981. Osmotic and structural changes during early development of eggs and larvae of the cod, Gadus morhua L. J. Fish. Biol., 19: 317-331.

EARLL, R. E. 1880. A report on the history and present condition of the shore cod fisheries of Cape Ann, Mass., together with notes on the natural history and artificial propagation of the species. Rep U.S. Comm. Fish and Fisheries for 1878, 6: 685-740.

FREDGEIRSSON, E. 1978. Embryonic development of five species of gadoid fishes in Icelandic waters. Rit. Fiskideild. 5: 1-68. 
GALAT, D. L. 1972. Preparing teleost embryos for study. Progr. Fish.Cult., 34: 43-48.

HARDY, J. D. 1978. Anguillidae through Syngnathidae. In Development of fishes of the mid-Atlantic Bight: an atlas of egg, larval and juvenile stages. (Vol. 2), Biol. Ser. Prog., U.S. Fish. Wildl. Serv., $458 \mathrm{p}$.

HEMPEL, G. 1965. On the importance of larval survival for the population dynamics of marine food fish. Rep. Calif. Ocean. Fish. Invest., 10: $13-23$.

1979. Early life history of marine fish: the egg stage. Univ. Wash. Press, Seattle, Wash., $70 \mathrm{p}$.

HOWELL, G. C. L. 1921. Ocean research and the great fisheries. Clarendon Press, Oxford, England, $220 \mathrm{p}$.

HUNTER, J. R. 1981. Feeding ecology and predation of marine fish larvae. In Marine fish larvae, morphology, ecology and relation to fisheries (p. 33-37), Univ. Wash. Press, Seattle, Wash., $131 \mathrm{p}$

LAALE, H.W. 1980. The perivitelline space and egg envelopes of bony fishes: a review. Copeia, 1980: 210-226.

MCINTOSH, W. C., and E. E. PRINCE. 1890. On the development and life histories of the teleostean food and other fishes. Trans. R. Soc. Edinb., 35: 665-946.

MCKENZIE, R. A. 1940. Nova Scotian autumn cod spawning. J. Fish. Res. Board Can., 5: 105-120.

MEEK, A. 1924. The development of the cod (Gadus callarias L.) Fish. Invest. Lond., Ser. 2, 7: 1-26.

MIDDAUGH, D. P., and T. TAKITA. 1983. Tidal and diurnal spawning cues in the Atlantic silverside, Menidia menidia. Environ. Biol. Fish., 8: 97-104.

NAKANO, E. 1969. Fishes. In Fertilization, comparative morphology, biochemistry and immunology (Vol. 2, p. 295-324), C. B. Metz and
A. Monroy (ed.), Academic Press, New York, N.Y., 489 p.

NAKATSURA, K., and D. L. KRAMER. 1982. Is sperm cheap? Limited male fertility and female choice in the lemon tetra (Pisces, Characidae). Science, 216: 753-755.

O'DOR, R. K., N. BALCH, E. A. FOY, R. W. M. HIRTLE, D. A. JOHNSTON, and T. AMARATUNGA. 1982. Embryonic development of the squid, Illex illecebrosus, and effect of temperature on development rates. J. Northw. Atl. Fish. Sci., 3: 41-45.

POSGAY, J. A., and R. R. MARAK. 1980. The MARMAP bongo zooplankton sampler. J. Northw. Atl. Fish. Sci., 1: 91-99.

ROLLEFSEN, G. 1930. Observations on cod eggs. ICES Rapp. Proc.Verb., 65: 31-34.

1932. The susceptibility of cod eggs to external influences. ICES J. Cons., 7: 367-373.

RYDER, J. A. 1884. A contribution to the embryology of osseous fishes, with special reference to the development of the cod (Gadus morhua). Rep. U.S. Comm. Fish and Fisheries for 1882, p. 455-605.

STAVN, R. H. 1971. The horizontal-vertical distribution hypothesis: Langmuir circulations and Daphnia distributions. Limnol. Oceanogr., 16: 453-466.

STOMMEL, H. 1949. Trajectories of small bodies sinking slowly through connection cells. J. Mar. Res., 8: 24-29.

WILLIAMS, G. C., D. C. WILLIAMS, and R. J. MILLER. 1973. Mortality rates of planktonic eggs of the cunner, Tautogolabrus adspersus (Walbaum), in Long Island Sound. In Proceedings of a workshop on egg, larval and juvenile stages of fish in Atlantic Coast estuaries (p. 181-195), A. L. Pacheco (ed.), U.S. Nat. Mar. Fish. Serv., Mid. Atl. Coast Fish Center, Tech. Publ. No. 1, 338 p.

YAMAMOTO, T. 1961. Physiology of fertilization in fish eggs. Int. Rev. Cytology, 12: 361-405. 
